\title{
As Relações Intersetoriais do Setor de Produção de Energia na Economia Gaúcha no Período de 1998 e 2003: uma Análise Insumo-Produto*
}

\section{The Intersectorial Relations of the Energy Production Industry in the Economy of Rio Grande do Sul: an Input-Output Analysis}

\author{
Marco Antonio Montoya** \\ Cássia Aparecida Pasqual*** \\ Nadia Mar Bogoni****
}

Resumo: O artigo avalia as relações intersetoriais do setor de produção de energia na economia do estado do Rio Grande do Sul. Para isso, foi construído o setor de produção de energia no modelo insumo-produto do estado para os anos de 1998 e 2003. Verificou-se que o setor utiliza majoritariamente insumos importados, apresenta um nível elevado de autoabastecimento e fornece pouco menos de $80 \%$ de sua produção para as indústrias do estado. Os encadeamentos setoriais e as relações entre a produção e demanda final apontam o setor de produção de energia como um setor-chave com fortes ligações para frente e mostram que sua produção apresenta elevada dependência em relação ao consumo das famílias e às exportações interestaduais. Portanto, conclui-se que o setor é um fornecedor importante de insumos básicos, cuja atividade produtiva estimula de forma abrangente e uniforme o crescimento dos diversos setores de produção e de consumo da economia gaúcha.

Palavras-chave: Produção de energia. Insumo-produto. Encadeamentos setoriais.

Abstract: The article evaluates the intersectorial relations of the Energy Production industry in the economy of the state of Rio Grande do Sul. For this, the Power

* Os resultados deste estudo fazem parte de um projeto maior intitulado Construção da matriz insumo-produto híbrida do estado do Rio Grande do Sul para avaliação setorial da intensidade energética e das emissões de $\mathrm{CO} 2$.

* $\quad$ Doutor em economia aplicada pela Escola Superior de Agricultura Luiz de Queiroz (Esalq) da Universidade de São Paulo (USP). Professor titular da Faculdade de Ciências Econômicas, Administrativas e Contábeis da Universidade de Passo Fundo (UPF). E-mail: montoya@upf.br

** $\quad$ Mestre em agronegócios pela Universidade Federal do Rio Grande do Sul (UFRGS). Professora assistente da Faculdade de Ciências Econômicas, Administrativas e Contábeis da Universidade de Passo Fundo (UPF). E-mail: cpasqual@upf.br

**** Mestre em Contabilidade pela Universidade Regional de Blumenau (Furb). Professora assistente da Faculdade de Ciências Econômicas, Administrativas e Contábeis da Universidade de Passo Fundo (UPF). E-mail: nbogoni@upf.br 
Generation sector was built in the state's input-output model for the years 1998 and 2003. It was found that the industry uses imported inputs mostly, shows a high level of self-supply and provides a little less than eighty percent of its production for the industries of the state. The sectorial linkages and the production and final demand relations indicate the Energy Production industry as a key sector with strong links to the front, and show that the Household consumption and Interstate exports have a high dependence of its production. Accordingly, we conclude that this sector is an important supplier of basic inputs which productive activity encourages, in an embracing and uniform way, the growth of several production and consumption sectors of the economy in the State of Rio Grande do Sul.

Keywords: Energy production. Input-output. Sectoral linkages

JEL Classification: Q41; D57; C67; R10.

\section{Introdução}

Previsões sobre a demanda de energia para o Rio Grande do Sul, com base na taxa de crescimento que apresenta o país (IEO, 2009), apontam, até o ano de 2030, que o consumo de energia crescerá a uma taxa de 2,6\% a.a. Em decorrência disso, estima-se que esse consumo passará de 14.178 milhões de toneladas equivalentes de petróleo (tep), em 1998, para 23.701 milhões de tep em 2030, ou seja, haverá um aumento de 167,16\% na dimensão do mercado energético do estado (BALANÇO ENERGÉTICO DO RIO GRANDE DO SUL, 2010, p. 33).

Frente a essas perspectivas, muito se tem discutido sobre o maior consumo de energia e o impacto ambiental da emissão de gases decorrentes do maior volume de produção e consumo. Porém, uma questão de suma importância e ainda pouco discutida de forma empírica no estado é: dado o crescente consumo de energia, quais são as relações insumo-produto que se estabelecem entre o setor de produção de energia e os demais setores de sua economia? De que maneira o setor energético se insere na estrutura de produção e consumo? Qual é a importância relativa do setor energético na promoção do crescimento econômico gaúcho?

Em razão da falta de evidência empírica sobre essa problemática, muito se pode especular a respeito, até porque não existe no corpo teórico da matriz insumo-produto do Rio Grande do Sul o setor de produção de energia, de forma desagregada, para análise de tais aspectos. Assim, considerando que o modelo insumo-produto tem a capacidade de retratar as relações setoriais em diferentes níveis de complexidade, acredita-se, nesta pesquisa, que é um instrumento adequado para avaliar as relações setoriais de produção e consumo de energia no estado.

Nesse sentido, este estudo se propõe, para os anos de 1998 e 2003, construir o setor de produção de energia no modelo insumo-produto do Rio Grande do 
Sul. Com base nesses dados, propõe-se também avaliar os fluxos de compra de insumos e de venda de produtos do setor energético e identificar a relevância de seus encadeamentos setoriais para o estímulo do crescimento, bem como sua dependência produtiva em relação aos componentes da demanda final. Com isso, espera-se fornecer subsídios para entender a abrangência das relações do setor de produção de energia com os diferentes setores determinantes do crescimento econômico do estado e, fundamentalmente, no futuro, quando avaliados os impactos ambientais, entender melhor o contexto intersetorial que existe no processo.

O presente artigo está dividido da seguinte maneira: na seção 2, é apresentado de forma resumida, o processo de construção do setor de produção de energia, os procedimentos para identificar encadeamentos relevantes e as relações entre a produção e os componentes da demanda final; a seção 3 caracteriza as relações insumo-produto por origem e destino do setor energético com os diversos setores produtivos do estado; a seção 4 avalia, através de índices de ligações, coeficientes de dispersão e índices de dependência setorial, a relevância do setor de energia para a economia gaúcha; na última seção, são apresentadas as principais conclusões obtidas no decorrer da análise.

\section{Metodologia}

\subsection{Estrutura do Modelo Insumo-Produto que Inclui o Setor Energético}

O instrumental de análise adotado nesta pesquisa baseia-se nas matrizes insumo-produto do Rio Grande do Sul de 1998 e 2003 construída pela FEE (MAIA NETO, 2002; PORSSE, 2007), entretanto, como essas matrizes não contemplam o setor de produção de energia, foi necessário, por um lado, deixar em evidência setores, como, por exemplo, derivados do petróleo. Por outro lado, foi preciso construí-lo, já que combustíveis energéticos e não energéticos, tais como biodiesel, derivados do álcool, graxas, parafinas, asfaltos, solventes, nafta, alcatrão, eletricidade, entre outros, não são especificados nas matrizes existentes. Para isso, tomaram-se como base as informações do Balanço Energético do Rio Grande do Sul 2010: ano base 2009 (CAPELETTO; MOURA, 2010).

O setor Energético do Rio Grande do Sul, de acordo com a descrição de seu balanço energético (CAPELETTO; MOURA, 2010, p. 215 e 221), está composto pela agregação das fontes de energia primária - tais como petróleo, gás natural, carvão vapor, carvão metalúrgico, urânio U308, energia hidráulica, lenha, produtos da cana e outras fontes primárias - e das fontes de energia secundária - compostas por óleo diesel, óleo combustível, gasolina, gás liquefeito do petróleo (GLP), nafta, querosene, gás de cidade e de coqueria, coque de carvão mineral, urânio contido no UO2, eletricidade, carvão vegetal, álcool etílico (anidro e hidratado), 
biodiesel - além de outras fontes secundárias de petróleo (gás de refinaria, coque), produtos não energéticos do petróleo (graxas, parafinas, asfaltos, solventes) e alcatrão.

A hipótese central para a construção do setor energético foi de que o fluxo anual por origem e destino de consumo de energia em tep dos diversos setores da economia, convertidos no equivalente preço médio, constitui-se em uma "proxy" consistente das transações setoriais do setor de produção de energia.

Para estimar o vetor das vendas do setor energético destinadas para a demanda intermediária e demanda final, foi necessário, com fins de evitar dupla contagem, o resgate dos valores do setor energético contido nos diversos setores do sistema econômico. Com esses fins, foram utilizados os clássicos modelos de coeficientes-linha de Hansen e Tiebout (1963) e Polenske (1970). Já para estimar o vetor das compras de insumos de outros setores, bem como de fatores primários e de importações na demanda intermediária, foram utilizados os clássicos modelos de coeficientes-coluna de Chenery (1953) e Moses (1955). Com a finalidade de respeitar os pressupostos de equilíbrio geral do modelo, foram utilizadas as técnicas de ajuste proposto por Montoya (1999, p. 82-85). Maiores informações sobre a construção do setor energético do Rio Grande do Sul pode ser encontrado em Montoya, Pasqual e Bogoni (2011). 


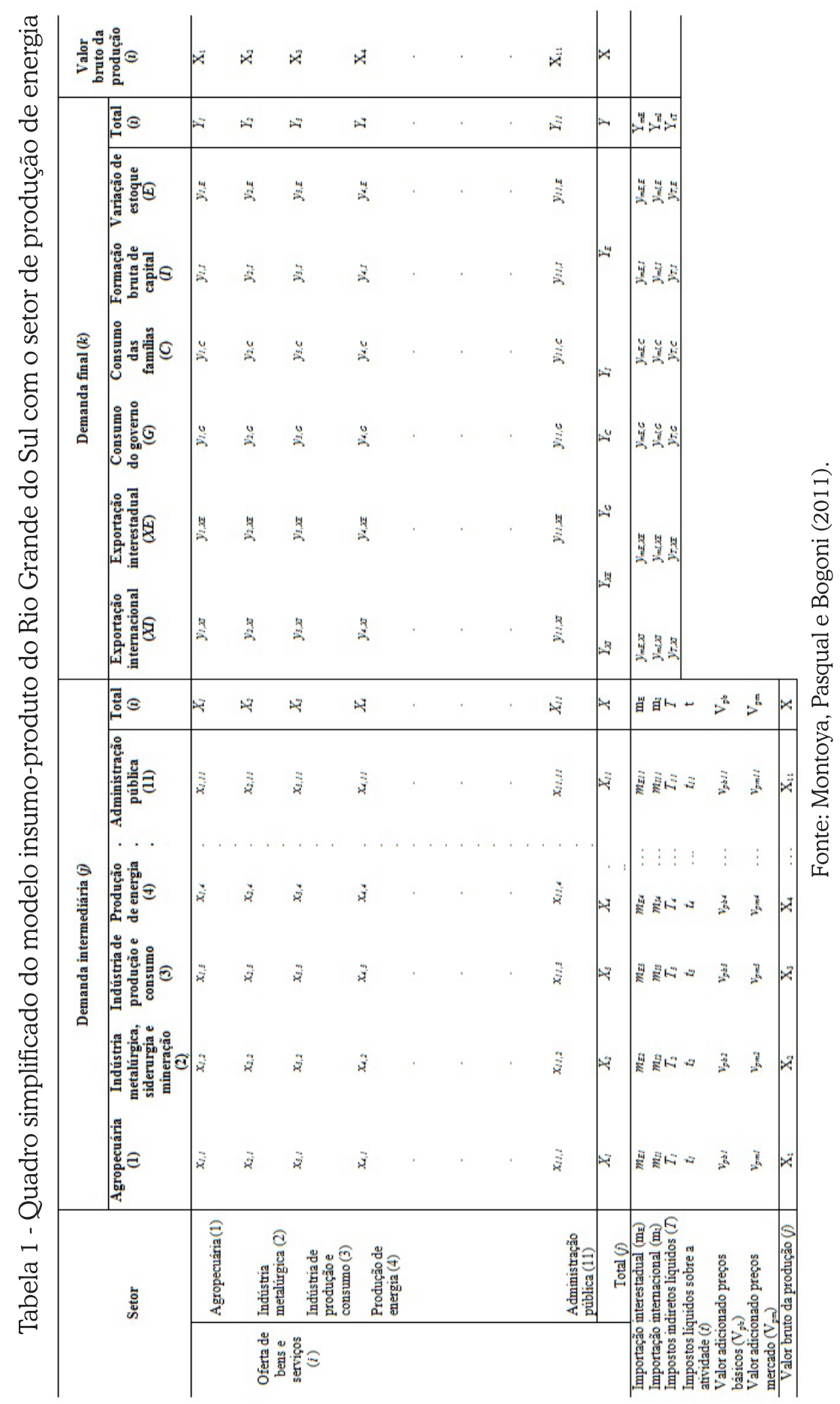


Nesse contexto, o modelo insumo-produto do Rio Grande do Sul para o ano de 1998 e 2003, que inclui o setor energético, representa um sistema econômico aberto que especifica 11 setores, que compatibilizam as matrizes insumo-produto econômica com a matriz energética. A estrutura dos fluxos insumo-produto é mostrada na Tabela 1. Na tabela, os setores da demanda localizados nas colunas são divididos em setores de demandas intermediárias e setores de demanda final. Os setores da demanda intermediária são subdivididos em dois grupos. O primeiro contém a produção setorial utilizada como insumos nos setores:

a) agropecuário

b) indústrias metalúrgicas, siderúrgica e mineração

c) indústria de bens de produção e consumo

d) produção de energia

e) celulose, papel e gráfica

f) químicos, farmacêuticos e veterinários

g) indústria de alimentos e bebidas

h) construção civil

i) comércio e serviços

j) transportes

k) administração pública

O segundo grupo está composto pelos fatores primários (VA) ou setores de suprimentos, tais como:

$m_{E}$ : importação interestadual

$m_{I}$ : importação internacional

$T$ : impostos indiretos líquidos

$t$ : impostos líquidos sobre a atividade

$V_{p b}$ : valor adicionado a preços básicos

$V_{p m}:$ valor adicionado a preços de mercado

Já os setores da demanda final são subdivididos em:

$X I$ : exportação internacional

$X E$ : exportação interestadual

$G$ : consumo do governo

C: consumo das famílias

I: formação bruta de capital

E: variação de estoque

Nota-se, com isso, que o quadro insumo-produto especifica a distribuição da produção de cada setor para os diversos setores do estado. Em particular, a estrutura de insumos comprados, na linha vertical, pelo setor de produção de energia (j) pode ser expressa através da seguinte relação contábil:

$$
x_{4}=x_{1,4}+x_{2,4}+x_{3,4}+\ldots+x_{1,4}+m_{E 1}+m_{I 1}+T_{1}+t_{1}+V p b_{1}
$$


As estruturas de insumo dos outros setores também podem ser expressas de forma similar.

Quanto à estrutura da demanda ou vendas, na linha horizontal, do setor de produção de energia (i), pode ser expressa através da seguinte relação contábil:

$$
x_{4}=x_{4,1}+x_{4,2}+x_{4,3}+\ldots+x_{4,11}+y_{4, \mathrm{XI}}+y_{4, \mathrm{XE}}+y_{4, \mathrm{G}}+y_{4, \mathrm{C}}+y_{4, \mathrm{I}}+y_{4, \mathrm{E}}
$$

Já as estruturas da demanda dos outros setores também podem ser expressas de maneira similar.

Generalizando, a estrutura de insumos para j-ésimo setor a equação (1) pode ser expressa da seguinte maneira:

$$
X_{j}=\sum_{i} x_{i j}+m_{E j}+m_{I j}+T_{j}+t_{j}+V p b_{j} \quad(i, j=1,2,3, \ldots, 11)
$$

ou

$$
X_{j}=\sum_{i} x_{i j}+\sum_{r} V A_{r j} \quad\left(r=m_{E}, m_{l}, T, t, V_{p b}, V_{p m} \text {, alternativamente }\right)
$$

Simultaneamente à generalização da estrutura de demanda do i-ésimo setor, a equação (2) pode ser expressa da seguinte maneira:

$$
X_{i}=\sum_{j} x_{i j}+\sum_{k} y_{i k} \quad(k=X I, X E, G, C, I, E \text { alternativamente })
$$

Desde que o valor total de insumos utilizados seja igual ao valor total de produtos ( $X_{j}=X_{i}$ ), o quadro insumo-produto será consistente.

No modelo insumo-produto, supõe-se que os coeficientes de produção são fixos, ou seja, os requerimentos de insumos intermediários têm uma participação fixa em relação ao valor bruto da produção dos setores. Os coeficientes técnicos $a_{i j}$ representam a quantidade do produto do setor $i$ requerida para produzir uma unidade no produto do setor j. Assim:

$$
a_{i j}=\frac{x_{i j}}{X_{j}} \quad \text { ou } \quad x_{i j}=a_{i j} X_{j}
$$

Em conjunto, esses coeficientes formaram a matriz $A$, que indica, simultaneamente, a estrutura tecnológica de cada setor e a estrutura de abastecimento setorial. 


$$
A=\left[\begin{array}{cccc}
a_{1.1} & a_{1.2} & \ldots & a_{1.11} \\
a_{2.1} & a_{2.2} & \ldots & a_{2,11} \\
\vdots & \vdots & \ldots & \vdots \\
a_{11.1} & a_{11.2} & \ldots & a_{11.11}
\end{array}\right] \quad(i, j=1,2,3, \ldots 11)
$$

Os requerimentos de fatores primários de produção (VA = valor adicionado + importações) também têm uma relação fixa com respeito ao valor bruto da produção total do setor j. Os coeficientes técnicos $b_{\dot{j}}$ representam a quantidade do fator primário $r$ requerida para produzir uma unidade de produto do setor $\mathrm{j}$. Assim:

$$
b_{r j}=\frac{V A_{r j}}{X_{j}} \quad \text { ou } \quad V A_{r j}=b_{r j} X_{j} \quad\left(r=m_{E}, m_{\mathrm{r}}, T, t, V_{p b}, V_{p m}, \text { alternativamente }\right)
$$

Substituindo as equações 6 e 8 na equação 4, obtém-se a equação 9, que, dividida por $X_{j}$, resulta na equação 10 .

$$
\begin{aligned}
& X_{j}=\sum_{i} a_{i j} X_{j}+\sum_{r} b_{r j} X_{j} \\
& \sum_{i} a_{i j}+\sum_{r} b_{r j}=1
\end{aligned}
$$

O modelo aberto de Leontief pode ser representado pela equação 11, que decorre da substituição da equação 6 na equação 5 e fazendo $\sum_{k} y_{i k}=Y_{i}$.

$$
\sum_{i} a_{i j} X_{j}+Y_{i}=X_{i} \quad \text { ou } \quad X_{i}-\sum_{j} a_{i j} X_{j}=Y_{i}
$$

Finalmente, a solução do modelo aberto para a produção setorial pode ser expressa em termos dos componentes da demanda final, expresso na equação 12.

$$
X_{i}=\left(I-\sum_{j} a_{i j}\right)^{-1} Y_{i}
$$

Os requerimentos da matriz inversa $\left(I-\sum_{j} a_{i j}\right)^{-1}$ são chamados de requerimentos totais de produção, ou seja, os requerimentos diretos e indiretos de produção. Eles indicam as mudanças na produção setorial necessárias para atender 
a uma determinada variação da demanda final. Nota-se que a demanda final do modelo é exógena, o que permite que se analisem de forma sistêmica o perfil da estrutura de transações, os efeitos multiplicadores decorrentes da demanda final, diferentes tipos de problemas que envolvem programas de investimentos, aumento do consumo, tributação, mudança tecnológica, etc.

\subsection{Estrutura Insumo-Produto do Setor de Energia}

Para avaliar a estrutura de compras e vendas do setor de produção de energia é necessário encontrar as proporções por origem e destino dos requerimentos setoriais $\left(H_{j}^{*}\right)$ e do fluxo de vendas para a demanda intermediária e final $\left(H_{i}^{*}\right)$.

$$
H_{j}^{*}=H_{i} / X_{j} \quad \text { e } \quad H_{i}^{*}=H_{j} / X_{i} \quad(i, j=1,2,3, \ldots 11)
$$

$H_{i}$ representa o vetor de insumos que o setor energia compra de cada setor;

$H_{\mathrm{j}}$ representa o vetor de vendas que o setor energia destina para a demanda intermediaria e demanda final e; energia.

$X_{j}$ e $X_{i}$ representam o valor bruto da produção do setor de produção de

\section{3 Índices de Rasmussen-Hirschman e Coeficientes de Bulmer-Thomas}

Os índices de ligações de Rasmussen (1956) e Hirschman (1958) permitem identificar os setores que teriam maior poder de encadeamento dentro da economia. Os índices de ligações para trás nos dizem o quanto um setor demanda dos outros, e os índices de ligações para frente nos dizem o quanto esse setor é demandado pelos outros. Valores maiores que 1 indicam setores acima da média, e, portanto, setores-chave para o crescimento da economia. A fim de complementar esses índices, pode-se associar a cada um deles os coeficientes de dispersão de Bulmer (1982). Um valor baixo de dispersão significa que o impacto de uma variação da produção num dado setor estimularia os outros setores de uma maneira uniforme, enquanto que um valor alto de dispersão significaria que o estímulo seria concentrado em poucos setores.

Desse modo, a partir da equação 12 , definimos $b_{i j}$ como sendo um elemento da matriz inversa de Leontief $\left(I-\sum_{j} a_{j}\right)$, ou simbolizado também como $B . B^{*}$ como sendo a média de todos os elementos de $B$ e $B_{*_{j}}, B_{i^{*}}$ como sendo, respectivamente, a soma de uma coluna e de uma linha típica de $B$. Temos, então, que os índices serão: 
Índices de ligações para trás:

$$
U_{j}=\left[B_{*_{j}} / n\right] / B^{*}
$$

Dispersão do índice de ligações para trás:

$$
V_{j}=\frac{\sqrt{\frac{\sum_{i}^{n}\left(b_{i j}-\frac{B_{* j}}{n}\right)^{2}}{(n-1)}}}{\frac{B_{* j}}{n}}
$$

Índices de ligações para frente:

$$
U_{i}=\left[B_{i *} / n\right] / B^{*}
$$

Dispersão do índice de ligações para frente:

$$
V_{i}=\frac{\sqrt{\frac{\sum_{j}^{n}\left(b_{i j}-\frac{B_{i^{*}}}{n}\right)^{2}}{(n-1)}}}{\frac{B_{i^{*}}}{n}}
$$

\subsection{Produção Induzida pelos Componentes da Demanda Final}

Para se calcular os efeitos derivados dos componentes da demanda final sobre a produção setorial, ou seja, o vetor que contém a produção induzida em $j$ pelo componente $k$ da demanda final $\left(H_{j}^{k}\right)$, conforme Montoya e Guilhoto (1998) e Montoya (2001), utiliza-se a equação 18.

$$
H_{j}^{k}=\left(I-\sum_{j} a_{i j}\right)^{-1} Y_{k}(k=X I, X E, G, C, I, E, \text { alternativamente })
$$


Estabelecidos os montantes de produção setorial induzida, é possível também estabelecer os níveis de dependência ou incidência setorial na produção ( $H_{i}^{k}$ ) do i-ésimo setor pelo $k$-ésimo componente da demanda final, ou seja,

$$
H_{j}^{k}=H_{i k} / H_{i}
$$

sendo $H_{i k}$ a produção induzida em i pelo componente $k$ da demanda final e $H_{i}$ a produção induzida total em i. Com esses cálculos, é possível examinar e distinguir o grau de influência que cada componente da demanda final exerce sobre o setor de produção de energia.

\subsection{Fonte e Natureza dos Dados}

Os dados utilizados para construir o setor de produção de energia foram extraídos das matrizes de insumo-produto do Rio Grande do Sul de 1998 e 2003 (MAIA NETO, 2002; PORSSE, 2007), do Balanço Energético do Rio Grande do Sul 2010 (CAPELETTO; MOURA, 2010), do banco de dados da Companhia Estadual de Energia Elétrica (2010) e das tabelas insumo-produto do estado que incluem o setor de produção de energia para 1998, construída por Montoya, Pasqual e Bogoni (2011).

A compatibilização das informações levou em consideração a Classificação Nacional de Atividades Econômicas (CNAE 2.0) do IBGE, bem como o grau de homogeneidade das atividades de cada setor. Como resultado se obteve uma agregação da matriz insumo-produto de (11 x 11) setores, dentre os quais um corresponde ao setor energético formado pelos setores de extração de petróleo e gás, Serviços Industriais de Utilidade Publica-SIUP (eletricidade e gás), refino do petróleo e indústria petroquímica, conforme o Anexo A. Esses setores na matriz de recursos e usos estão compostos por atividades, tais como: petróleo e gás natural; carvão mineral; produtos das usinas e do refino de açúcar; GLP; gasolina automotiva; gasoálcool; óleo combustível; óleo diesel; outros produtos do refino de petróleo e coque; álcool; produtos químicos orgânicos; eletricidade e gás; água, esgoto e limpeza urbana. Essa agregação setorial que evidencia somente as atividades energéticas permite avaliar o uso de energia setorial na economia gaúcha.

A compatibilização setorial da matriz insumo-produto do estado com sua matriz energética constam de forma resumida nos Anexos $\mathrm{A}, \mathrm{B}$ e $\mathrm{C}$, nos quais apresentam-se as matrizes insumo-produto compiladas que foram a base de dados desta pesquisa. As matrizes insumo-produto utilizadas refletem um modelo regional, adotam o enfoque setor $x$ setor a preços aproximadamente básicos, com tecnologia baseada na indústria, estando seus valores para análise comparativa em milhões de reais de 2010. 


\section{Estrutura de Compras e Vendas do Setor Energético Gaúcho}

Um dos propósitos de análise de insumo-produto neste artigo é o esclarecimento das relações que se estabelecem com o comércio entre o setor de produção de energia com os demais setores do estado do Rio Grande do Sul, isso porque a interdependência comercial faz com que as indústrias usem energia doméstica e importada como insumos, mesmo que estejam disponíveis domesticamente ou não.

Sob essa perspectiva, as transações entre as indústrias do estado do Rio Grande do Sul em 1998 e 2003, contidas nos Anexos B e C, mostram as demandas intermediárias por insumos e as demandas finais por produtos. Essas informações permitem, inicialmente, que se estabeleçam alguns parâmetros sobre a dimensão econômica do setor de produção de energia. Do ponto de vista do Valor Bruto da Produção, verifica-se que o setor energético, em relação à economia gaúcha, representa para os anos de 1998 e 2003 somente 1,72\% (ou 4.365 milhões de reais) e 4,12\% (ou 17.717 milhões de reais) respectivamente. Do ponto de vista do valor adicionado ou do PIB, o setor energético apresenta também, para o período, uma participação marginal de $0,45 \%$ (ou 698 milhões de reais) e 1,73\% (ou $3.211 \mathrm{mi-}$ lhões de reais), respectivamente.

Com base nesses fatos, pode-se argumentar que a oportunidade, relacionada à maior geração de renda, via aumento da demanda de produtos e serviços, parece substancialmente maior para outros setores da economia do que para o setor de produção de energia. Entretanto, é necessário para entender melhor a inserção estratégica do setor de energia na economia avaliar sua estrutura de compras e vendas setoriais, uma vez que, se faltar energia para o sistema produtivo, a maior renda dos outros setores poderá não se concretizar.

\subsection{Evolução Setorial do Consumo de Insumos do Setor de Produção de Energia}

Embora a análise da estrutura da produção e do consumo de energia da economia gaúcha esteja focada nas transações setoriais e, portanto, no VBP, cabe salientar que, em termos de tep, no período correspondente entre 1998 e 2003, a economia apresentou uma variação percentual de $16,22 \%$, o que equivale a uma taxa média de crescimento de 3,01\% a.a. (Tabelas 2 e 3). Já quando analisada a evolução do VBP do setor energético, como esperado conceitualmente, a variação percentual no período foi de $305,87 \%$, a uma taxa de crescimento de $28,02 \%$ a.a.

A comparação da expansão do consumo de energia em unidades físicas e em unidades monetárias alerta a necessidade de avaliar os dados monetários com relativa cautela dada a sobrevalorização do barril de petróleo no período que passou de 14,39 dólares, ou 16,70 reais, em 1998, para 31,14 dólares, ou 96,22 reais, em 2003. Com base nesse fato, a análise setorial a seguir centrará sua atenção às 
participações relativas que dizem respeito às informações mais estruturais da produção e consumo.

Feitas essas considerações, as informações da estrutura de compra de insumos que o setor de produção de energia faz para desenvolver suas atividades mostram, para o ano de 1998, que somente 10,60\% (ou 463 milhões de reais) de seus insumos são comprados no estado, sendo que, desse subtotal, o mesmo setor se autoabastece com $6,63 \%$, seguido de longe pelo setor de comércio e serviços, com $1,61 \%$, o que equivale, respectivamente, a $62,57 \%$ (ou 289 milhões de reais) e 15,23\% (ou 70 milhões de reais) dos insumos domésticos. De fato, o estado do Rio Grande do Sul apresenta uma dependência elevada por insumo de origem externa já que $73,40 \%$ (ou 3.204 milhões de reais) dos insumos que usa são importados, em particular de outros estados brasileiros (54,77\% ou 2.391 milhões de reais). As remunerações salariais, contribuições, rendimentos, entre outros contidos no valor adicionado a preços básicos, mostram uma participação de 16,00\% (ou 698 milhões de reais). Embora as compras de insumos do setor energético para o ano de 2003 não apresente mudanças estruturais significativas, verifica-se, por um lado, que o nível de autoabastecimento do setor aumentou, passando para $7,51 \%$, o que equivale a $77,24 \%$ (ou 1.330 milhões de reais) dos insumos do estado. Por outro, a dependência por insumos importados diminuiu levemente, passando para 72,16\% (ou 12.784 milhões de reais), em função da redução relativa das importações interestaduais, de 4,97 pontos percentuais, passando para 49,80\%. Já os insumos primários contidos no valor adicionado aumentaram sua contribuição, passando a representar 18,12\% (ou 3.211 milhões de reais) dos insumos totais que utiliza o setor energético. 


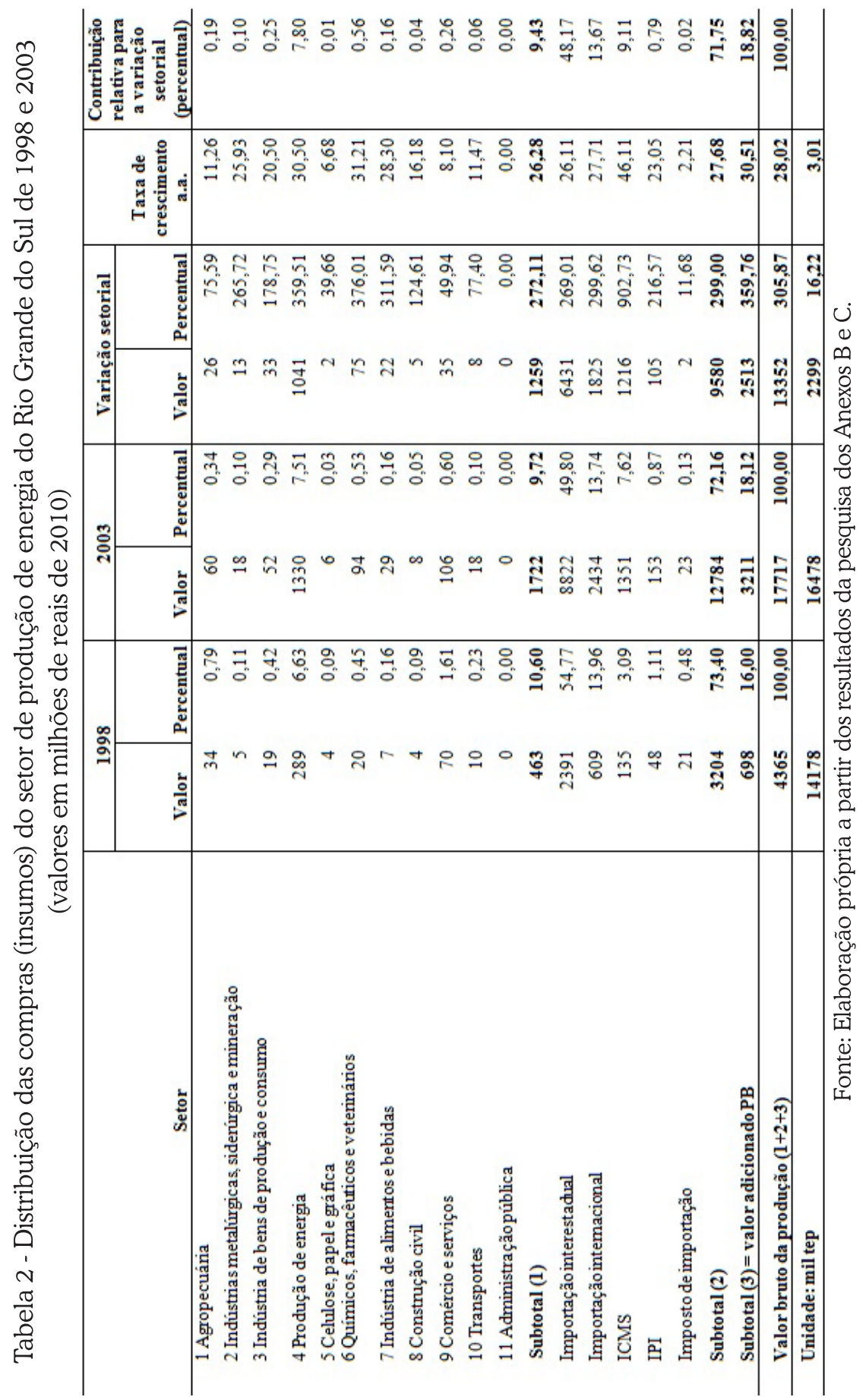


A análise setorial das taxas de crescimento evidencia que os setores de químicos, farmacêuticos e veterinários $(31,21 \%$ a.a.), de produção de energia $(30,50 \%$ a.a.) e de indústria de alimentos e bebidas $(28,30 \%$ a.a.) cresceram acima da taxa de crescimento da economia gaúcha $(28,02 \%$ a.a.). Isto é, as taxas de crescimento destacam no período os setores do estado que mais rapidamente expandiram o fornecimento de insumos para o setor de produção de energia. Contudo, deve-se salientar que e a arrecadação de ICMS sobre as importações $(46,11 \%$ a.a.) teve a maior expansão no estado.

No tocante à contribuição para a variação setorial, destacam-se, por sua magnitude, as importações interestaduais e as importações internacionais, que tiveram um acréscimo de $48,17 \%$ e $13,67 \%$, respectivamente, constituindo-os como o suprimento mais dinâmico na evolução setorial líquida. Em terceiro lugar, destaca-se o valor adicionado, com $18,82 \%$, seguido pelo ICMS, com $9,11 \%$, e pelo setor de produção de energia, com 7,80\%. Em conjunto, esses setores contribuem com 97,57\% da variação líquida total de insumos para a produção de energia.

\subsection{Evolução Setorial das Vendas do Setor Produção de Energia}

Conforme a Tabela 3, a dimensão econômica estabelecida pela estrutura de vendas do setor de produção de energia mostra, para o ano de 1998 , que $74,26 \%$ (ou 3.242 milhões de reais) de sua produção, na forma de insumos, é destinada para o consumo intermediário dos setores produtivos do estado e que $25,75 \%$ (ou 1.123 milhões de reais) é destinada, como produto, para o consumo final. Assim, considerando que o crescimento econômico tem um relevante papel no aumento do consumo de energia, verifica-se pelo montante de energia destinado aos diversos setores produtivos a importância relativa do setor de produção de energia como fornecedor de insumos básicos do estado.

No lado da demanda intermediária, o setor de transportes (com $24,75 \%$, ou 1.080 milhões de reais) se destaca como o maior consumidor de energia do estado, seguido pelo setor da agricultura (com 10,49\%, ou 458 milhões de reais), pelas indústrias de alimentos e bebidas (com 10,36\%, ou 452 milhões de reais), pelo próprio setor de produção de energia (com $6,63 \%$, ou 289 milhões de reais) e pelo setor de indústria de bens de produção e consumo (com 5,32\%, ou 232 milhões de reais). Em conjunto, os cinco setores consomem $57,55 \%$ do total de energia produzida no estado, o que evidencia um alto grau de dependência setorial pelo insumo energia.

No lado da demanda final, destaca-se o componente consumo das famílias, com 19,40\% (ou 847 milhões de reais), seguido de longe pelas exportações interestaduais, com 4,81\% (ou 210 milhões de reais). Certamente, pelo peso das famílias, percebe-se que o consumo residencial se constitui num componente importante que pressionará de forma direta e indireta a produção de energia à medida que se incremente a renda familiar do estado. 


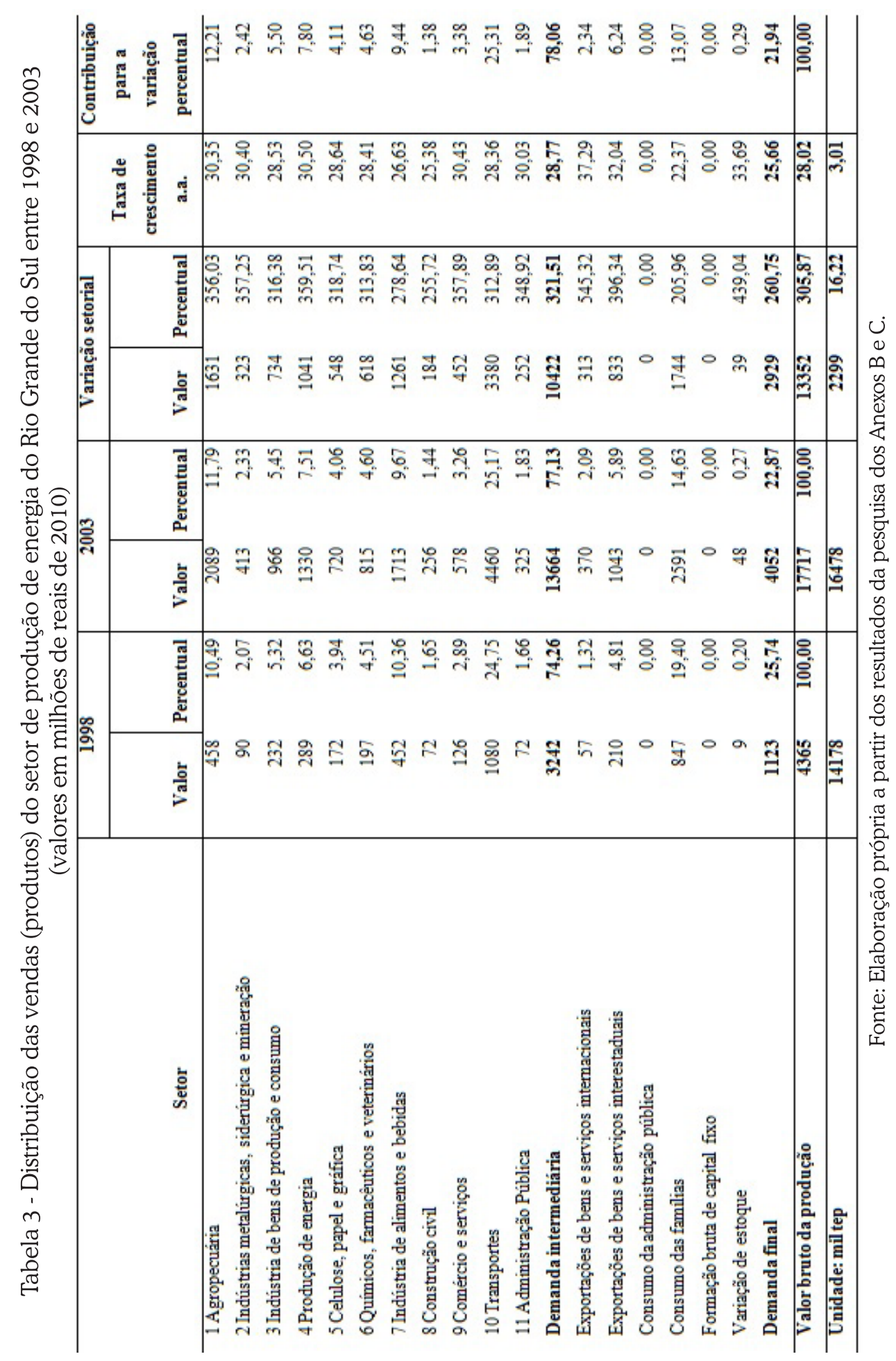


Para o ano de 2003, em geral, os fluxos de vendas do setor energético não apresenta mudanças estruturais significativas, já que a ordem de consumo de energia não se modificou. Contudo, verifica-se que os setores da demanda intermediária aumentaram sua participação relativa com relação a 1998, passando a consumir de $74,26 \%$ para $77,13 \%$ (ou 13.664 milhões de reais) do total de energia produzida no estado. Em virtude disso, a demanda final no período diminuiu sua participação de $25,74 \%$ para $22,87 \%$ (ou 4052 milhões de reais): nesse ajuste o componente consumo das famílias reduziu sua participação de $19,40 \%$ para 14,63\% em decorrência, principalmente, do componente exportação interestadual, que aumentou sua participação de $4,81 \%$ para $5,89 \%$.

As análises das taxas de crescimento setorial ao ano destacam no período os setores produtivos do estado que mais rapidamente expandiram o consumo de energia. Nesse sentido, destacam-se os setores de produção de energia (30,50\% a.a.), comércio e serviços (30,43\% a.a.), indústrias metalúrgicas, siderúrgica e mineração (30,40\% a.a.), Agropecuária (30,35\% a.a.) e Administração Pública (30,03\% a.a.), que cresceram acima da taxa média estadual do consumo intermediário ( $28,77 \%$ a.a.). Já as taxas dos componentes da demanda final destacam maior crescimento no consumo de energia às exportações internacionais $(37,29 \%$ a.a.) e interestaduais (32,04\% a.a.), bem como às da variação de estoque (33,69\% a.a.). Embora o consumo das famílias tenha crescido a uma taxa de $22,37 \%$ a.a., foi menos que a media da demanda final (25,66\% a.a.).

Com relação à contribuição para a variação setorial, destaca-se em primeiro lugar o setor de transportes (25,31\%), seguido pelo de consumo das famílias (13.07\%) e pelo agropecuário (12,21\%), que em conjunto contribuem com 50,59\% da variação líquida total do consumo de energia no estado.

O conjunto de informações sobre a estrutura de compras e vendas setoriais do setor de produção de energia permite assinalar os seguintes fatos: a) o VBP e o valor adicionado do setor energético apresenta uma pequena participação no estado; b) o setor energético em seu processo de produção caracteriza-se sobremaneira por utilizar maioritariamente insumos importados $(73,40 \%)$, bem como por apresentar um nível elevado e crescente de autoabastecimento de insumos; c) mais de dois terços da produção de energia é consumido pelas indústrias do estado, o que caracteriza o setor energético como um grande fornecedor de insumos para a produção; d) o consumo das famílias tem um peso significativo na demanda final de energia, embora se deva salientar a importância do setor de produção de energia como exportadora, em particular para outros estados do país. Fica evidente, portanto, que embora o setor de produção de energia tenha uma participação marginal no VBP e no PIB do estado, pode-se afirmar, num primeiro momento, com base nos indicadores avaliados, que a importância do setor radica 
no fornecimento de insumos para as indústrias e no fornecimento de produtos para o consumo final.

\section{Os Encadeamentos Setoriais e a Produção de Energia Induzida pela Demanda Final}

A análise do processo de interdependência setorial além de permitir caracterizar as estruturas de produção e consumo permite também determinar quais seriam os setores que teriam maior poder de encadeamento dentro da economia para promover o crescimento econômico, ou seja, os setores-chave. A identificação desses setores está associada à ideia de estabelecer prioridades na alocação de recursos e na estratégia de promoções industriais. Isso porque se espera que os recursos alocados em setores-chave, dependendo da política a ser implementada, estimulem um crescimento mais rápido da produção, do emprego e da interdependência econômica do que se fossem alocados em outros setores.

Nesse contexto, considerando estritamente a estrutura interna da economia, questiona-se: entre os setores da economia gaúcha, qual é o poder de encadeamento que apresenta o setor de produção de energia?

A seguir são apresentados nas Tabelas 4 e 5 e, nos Gráficos 1 e 2, os índices de ligações para trás e para frente dos setores do Rio Grande do Sul para os anos de 1998 e 2003. Os índices de ligações para trás indicam quanto um setor demanda dos outros, e os índices de ligações para frente indicam quanto este setor é demandado pelos outros. Já esses índices de ligações associados aos coeficientes de dispersão baixos mostram que a variação da produção no setor estimula os outros setores de uma maneira abrangente e uniforme, enquanto que um índice de dispersão alto mostra que o estímulo do setor seria concentrado em poucos setores.

\section{1 Índices de Ligações para trás e seus Coeficientes de Dispersão}

Dentre os diversos setores da economia, tanto para o ano de 1998, quanto para 2003, percebe-se, por um lado, que os índices de ligações para trás do setor de produção de energia são os menores do estado, com 0,83319 e 0,70615, respectivamente, ocupando a última posição (ordem $11^{\mathrm{a}}$ ) e, por outro, que os coeficientes de dispersão são os maiores do estado, com 3,13585 e 3,19202, respectivamente, ocupando a primeira posição (ordem $1^{\text {a }}$ ). Esses indicadores em conjunto, por apresentar ligações menores do que um e coeficientes elevados, descartam os encadeamentos para trás do setor de produção de energia como chave para o crescimento da economia gaúcha. 
Tabela 4 - Índices de ligações de Rasmussen-Hirschman e coeficientes de dispersão de Bulmer para o ano de 1998

\begin{tabular}{|c|c|c|c|c|c|c|c|c|c|}
\hline & \multirow{2}{*}{ MIP RS 1998 - Setor } & \multicolumn{4}{|c|}{ Ligações para trás } & \multicolumn{4}{|c|}{ Ligações para frente } \\
\hline & & Indice & Ordem & Dispersão & Ordem & Indice & Ordem & Dispersão & Ordem \\
\hline 1 & Agropecuária & 0,97130 & 6 & 2,78540 & 5 & 1,16864 & 3 & 2,39706 & 10 \\
\hline 2 & $\begin{array}{l}\text { Indústrias metalúrgicas, } \\
\text { siderúrgica e mineração }\end{array}$ & 0,91132 & 8 & 2,94685 & 3 & 0,86057 & 8 & 3,13547 & 4 \\
\hline 3 & $\begin{array}{l}\text { Indústria de bens de produção e } \\
\text { consumo }\end{array}$ & 1,02319 & 4 & 2,57634 & 9 & 0,95866 & 5 & 2,76024 & 7 \\
\hline 4 & Produção de energia & 0,83319 & 11 & 3,13585 & 1 & 1,01193 & 4 & 2,53425 & 9 \\
\hline 5 & Celulose, papel e gráfica & 0,98992 & 5 & 2,76141 & 6 & 0,86650 & 7 & 3,18479 & 3 \\
\hline 6 & $\begin{array}{l}\text { Químicos, farmacêuticos e } \\
\text { veterinários }\end{array}$ & 1,16174 & 2 & 2,78763 & 4 & 1,20307 & 2 & 2,67676 & 8 \\
\hline 7 & Indústria de alimentos e bebidas & 1,22326 & 1 & 2,11392 & 11 & 0,81161 & 9 & 3,12909 & 5 \\
\hline 8 & Construção civil & 0,96353 & 7 & 2,62287 & 8 & 0,78684 & 10 & 3,26535 & 2 \\
\hline 9 & Comércio e serviços & 0,91077 & 9 & 3,09131 & 2 & 1,65355 & 1 & 1,56728 & 11 \\
\hline 10 & Transportes & 1,10463 & 3 & 2,45172 & 10 & 0,93999 & 6 & 2,90162 & 6 \\
\hline 11 & Administração pública & 0,90714 & 10 & 2,67755 & 7 & 0,73863 & 11 & 3,31662 & 1 \\
\hline
\end{tabular}

Fonte: Elaboração própria a partir dos resultados da pesquisa.

Gráfico 1 - Índices de Ligações de Rasmussen-Hirschman e Coeficientes de Dispersão de Bulmer para o ano de 1998

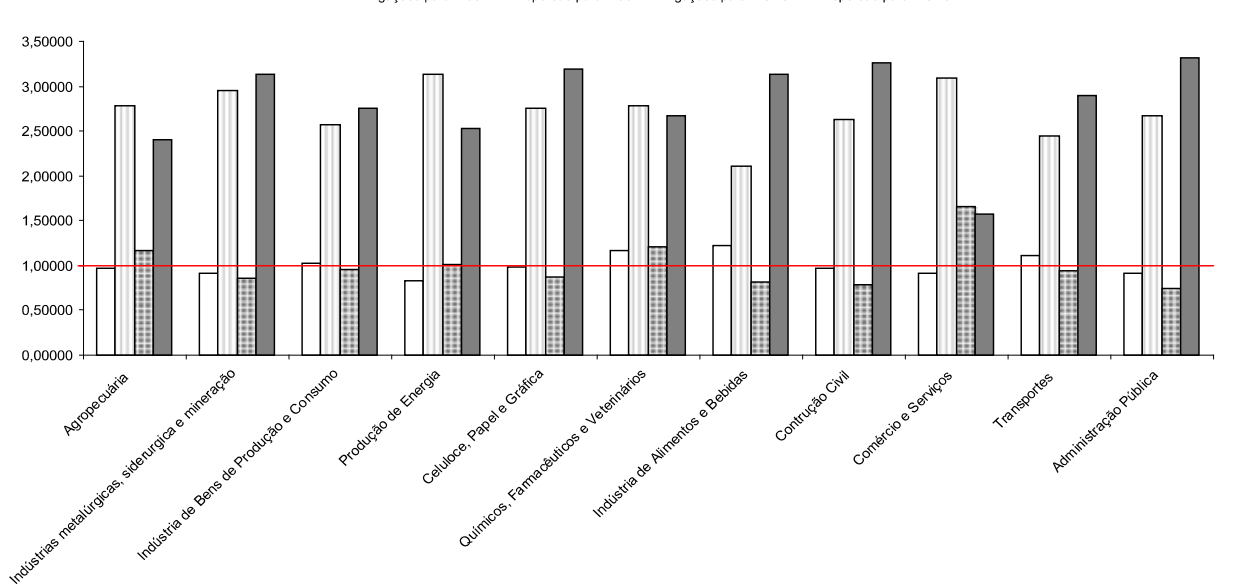

Fonte: Elaboração própria a partir dos resultados da pesquisa, com base na Tabela 4.

De fato, os índices demostram que se trata de um setor com encadeamentos setoriais de compra pouco relevantes dentro da economia gaúcha e seus estímulos, nos diversos setores da economia, pelo aumento da produção de energia são pequenos e concentrados em poucos setores. Nesse sentido, a análise da estrutura de compras do setor de produção de energia apontava para essa evidência já que grande parte dos insumos que utiliza em sua produção são importados, o que estimula outros sistemas econômicos e apresenta também um nível elevado 
e crescente de autoabastecimento de insumos domésticos, o que concentra seus estímulos.

\section{2 Índices de Ligações para Frente e seus Coeficientes de Dispersão}

Analisando as ligações para frente que indicam quanto um setor é demandado pelos outros setores, verifica-se, para o ano de 1998 e 2003, que o setor de produção de energia apresenta índices maiores do que 1 , o que lhe confere a categoria de setor-chave para o crescimento da economia.

Tabela 5 - Índices de ligações de Rasmussen-Hirschman e coeficientes de dispersão de Bulmer para o ano de 2003

\begin{tabular}{|c|c|c|c|c|c|c|c|c|c|}
\hline & \multirow{2}{*}{ MIP RS 200 - Setor } & \multicolumn{4}{|c|}{ Ligações para trás } & \multicolumn{4}{|c|}{ Ligações para frente } \\
\hline & & Indice & Ordem & Dispersão & Ordem & Indice & Ordem & Dispersão & Ordem \\
\hline 1 & Agropecuánia & 0,93560 & 7 & 2,35106 & 6 & 1,02184 & 4 & 2,28167 & 8 \\
\hline \multirow[t]{2}{*}{2} & Indústrias metalúrgicas, & & & & & & & & \\
\hline & siderúrgica e mineração & 0,93422 & 8 & 2,45449 & 4 & 0,87335 & 6 & 2,65107 & 6 \\
\hline \multirow[t]{2}{*}{3} & Indústria de bens de produção e & & & & & & & & \\
\hline & consumo & 1,08669 & 4 & 2,27317 & 7 & 1,01606 & 5 & 2,42699 & 7 \\
\hline 4 & Produção de energia & 0,70615 & 11 & 3,19202 & 1 & 1,24947 & 3 & 1,73983 & 10 \\
\hline 5 & Celulose, papel e gráfica & 0,98551 & 5 & 2,24746 & 8 & 0,72055 & 9 & 3,13647 & 2 \\
\hline \multirow[t]{2}{*}{6} & Químicos, farmacêuticose & & & & & & & & \\
\hline & veterinánios & 1,19192 & 2 & 2,69756 & 2 & 1,67790 & 1 & 1,82944 & 9 \\
\hline 7 & Indústria de alimentos e bebidas & 1,31423 & 1 & 1,82445 & 11 & 0,82551 & 7 & 2,88946 & 4 \\
\hline 8 & Construção civil & 0,97611 & 6 & 2,16360 & 9 & 0,70414 & 10 & 3,08931 & 3 \\
\hline 9 & Comércio e serviços & 0,91457 & 9 & 2,61752 & 3 & 1,47081 & 2 & 1,51568 & 11 \\
\hline 10 & Transportes & 1,11359 & 3 & 1,96280 & 10 & 0,81045 & 8 & 2,65901 & 5 \\
\hline 11 & Administraçãopública & 0,84140 & 10 & 2,44213 & 5 & 0,62995 & 11 & 3,31662 & 1 \\
\hline
\end{tabular}

Fonte: Elaboração própria a partir dos resultados da pesquisa.

Em particular, para o ano de 1998, a importância relativa dos encadeamentos para frente posiciona o setor energético em quarto lugar, com um índice de 1,01193. Para o ano de 2003, o setor continua sendo um dos mais demandados, só que com alteração de sua posição: o setor agropecuário, que estava em terceiro lugar, cedeu espaço para o setor de produção de energia, que apresentou um índice de 1,24947. Esses resultados indicam que o setor vem cada vez mais se constituindo como um dos principais fornecedores de insumos para outros setores, já que seu índice de ligação para frente aumentou em 23,47\% no período. 


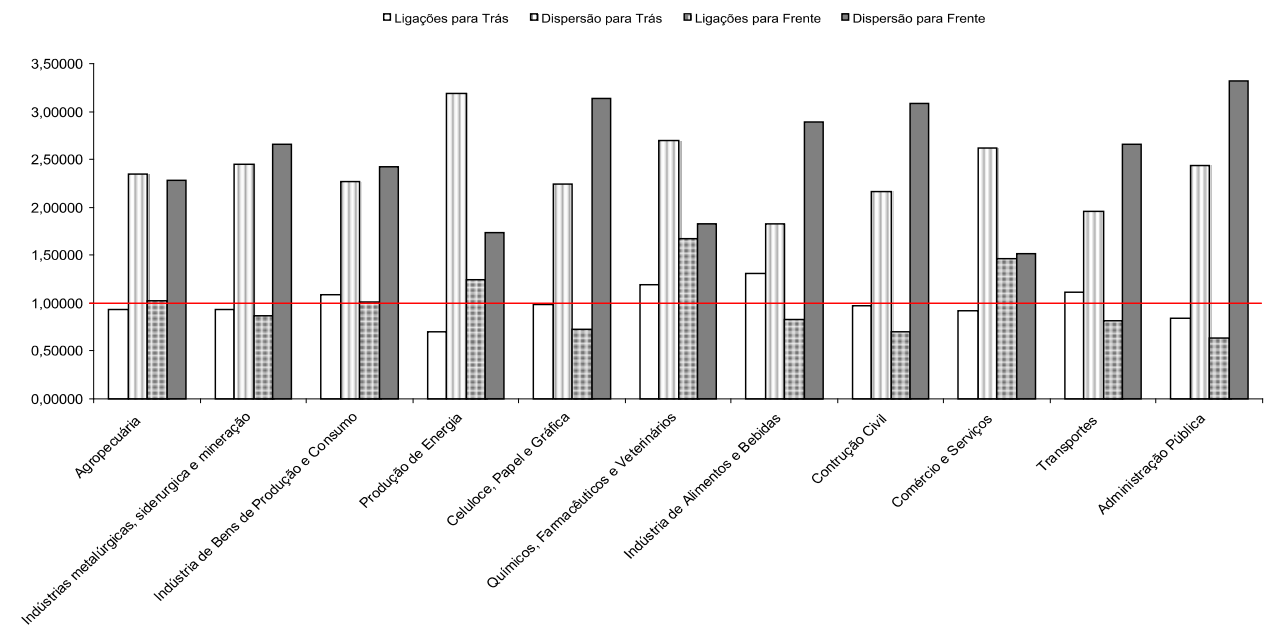

Fonte: Elaboração própria a partir dos resultados da pesquisa, com base na Tabela 5 .

Quando analisados os coeficientes de dispersão dos índices de ligações para frente, verifica-se, para o ano de 1998, que o setor produção de energia apresenta um valor baixo de dispersão (2,53425), ocupando o nono lugar (ordem $9^{a}$ ). Esse coeficiente demostra que o setor energético é fortemente demandado pelos outros setores da economia, de maneira abrangente e uniforme. Para o ano de 2003, novamente, o setor de produção de energia ganhou maior destaque com um coeficiente de 1,73983 , passando para o décimo lugar (ordem $10^{\circ}$ ). Certamente, os elevados índices de ligações para frente com baixos coeficientes de dispersão lhe conferem ao setor de produção de energia o status de um setor-chave fornecedor de insumos básicos que estimula de forma abrangente e uniforme a geração de riqueza nos demais setores produtivos da economia gaúcha.

Nesse quadro geral, o conjunto de informações sobre os encadeamentos do setor de produção de energia permite afirmar que: a) a baixa dependência do setor por insumos estaduais faz com que variações na sua produção estimulem pouco e de forma concentrada os setores da economia, ou seja, suas ligações para trás são fracas; b) a alta dependência por insumos energéticos dos diversos setores produtivos fazem com que a produção de energia seja um setor-chave, com ligações para frente, ou seja, um importante fornecedor de insumos básicos para a indústria e, portanto, para o crescimento econômico da economia gaúcha.

\subsection{Produção Induzida pelos Componentes da Demanda Final no Setor Energia}

A análise do processo de interdependência setorial está baseada no fato de que um produto não serve somente para atividades produtivas, mas também para 
satisfazer as necessidades da demanda final. Assim, nesta seção, questiona-se de que maneira os componentes da demanda final afetam o setor de produção de energia.

A Tabela 6 resume as quantidades de produção induzida no setor energia por componente da demanda final: as colunas mostram quanta produção cada componente da demanda final do estado gera no setor para os anos de 1998 e 2003; as linhas indicam em percentuais quanta produção de energia foi induzida por cada componente da demanda final, ou seja, o grau de influência ou dependência que cada componente da demanda final exerce sobre o setor energia. Já a consistência dos cálculos pode ser verificada, comparando-se a coluna dos totais da produção induzida do setor energia com a coluna da MIP de 1998 e 2003 que contém o VBP do setor de energia (Anexos B e C).

Tabela 6 - Produção induzida pelos componentes da demanda final no setor de produção de energia do Rio Grande do Sul nos anos de 1998 e 2003 (Valores em milhões de reais de 2010)

\begin{tabular}{|c|c|c|c|c|c|c|c|c|}
\hline \multirow{2}{*}{\multicolumn{2}{|c|}{ MIIP 1998 e 2003}} & \multicolumn{7}{|c|}{ Componentes da demanda final } \\
\hline & & $\begin{array}{c}\text { Exportações } \\
\text { internacionais }\end{array}$ & $\begin{array}{c}\text { Exportações } \\
\text { interestaduais }\end{array}$ & $\begin{array}{c}\text { Consumo da } \\
\text { administração } \\
\text { pública }\end{array}$ & $\begin{array}{c}\text { Consumo } \\
\text { das familias }\end{array}$ & $\begin{array}{c}\text { Formação } \\
\text { bruta de } \\
\text { capital fixo }\end{array}$ & $\begin{array}{l}\text { Variação } \\
\text { de estoque }\end{array}$ & $\begin{array}{c}\text { Total = VBP } \\
\text { do setor } \\
\text { energético }\end{array}$ \\
\hline \multirow[b]{2}{*}{$\begin{array}{c}\text { Produção } \\
\text { induzida } \\
1998\end{array}$} & Valor & 388 & 1.633 & 118 & 2.007 & 151 & 68 & 4.365 \\
\hline & Percentual & 8,88 & 37,42 & 2,71 & 45,97 & 3,47 & 1,55 & 100,00 \\
\hline \multirow{2}{*}{$\begin{array}{c}\text { Produção } \\
\text { induzida } \\
2003\end{array}$} & Valor & 2.209 & 7096 & 614 & 6729 & 648 & 420 & 17.717 \\
\hline & Percentual & 12,47 & 40,05 & 3,47 & 37,98 & 3,66 & 2,37 & 100,00 \\
\hline $\begin{array}{l}\text { Variação } \\
\text { liquida }\end{array}$ & Valor & 1.822 & 5.463 & 496 & 4.722 & 496 & 353 & 13.352 \\
\hline
\end{tabular}

Fonte: Elaboração própria a partir dos resultados da pesquisa, com base nos Anexos D e E.

Os resultados expressos na Tabela 6 destacam, em termos globais, que a produção do setor energético apresenta, para o ano de 1998, uma dependência de $47,97 \%$ (ou 2.007 milhões de reais) pelo consumo das famílias (36,59\%) e de $37,42 \%$ \% (ou 1.633 milhões de reais) pelas exportações interestaduais, perfazendo em conjunto uma influência na ordem de $83,39 \%$ sobre a produção de energia do estado. Em terceiro lugar, aparecem as exportações internacionais, com 8,88\% (ou 388 milhões de reais), seguida pela formação bruta de capital, com 3,47\% (ou 151 milhões de reais), e pela variação de estoque, com 1,55\% (ou 68 milhões de reais). Fica evidente também pelas informações que o perfil exportador da economia gaúcha pressiona significativamente a produção de energia, já que, do total produzido, 46,30\% é consumido pelas exportações destinadas para outros estados e para o mercado internacional.

A dependência do setor energético para o ano de 2003 apresenta mudanças significativas em todos os componentes da demanda final, principalmente nas 
exportações e no consumo familiar. Isto é, verifica-se, em geral, que com exceção do componente consumo das famílias, os demais componentes aumentaram sua influência sobre o setor de produção de energia.

Em particular, destacam-se a dependência do setor pelas exportações interestaduais, que aumentaram de $37,42 \%$ para $40,04 \%$ (ou 7.096 milhões de reais), seguido pelas exportações internacionais, que aumentaram de 8,88\% para $12,47 \%$ (ou 2.209 milhões de reais). Em decorrência disso, o componente consumo das famílias recuou, significativamente de $45,97 \%$ para $37,98 \%$ (ou 6.729 milhões de reais). Certamente isso se explica pela variação líquida do componente exportação interestadual no período que aumentou em 5.463 milhões de reais, valor superior ao dos demais componentes da demanda final.

Sob o particular, à contribuição dos componentes da demanda para a variação líquida da produção induzida, destacam-se como os mais dinâmicos para o crescimento do setor energético, em primeiro lugar, as exportações interestaduais, com uma participação relativa de $40,91 \%$, seguido pelo consumo das famílias, com $35,37 \%$, e pelas exportações internacionais, com $13,54 \%$.

Nesse contexto, pode-se afirmar que o setor de produção de energia se insere na economia do estado abastecendo o mercado doméstico, nacional e internacional, ou seja, o setor evidencia uma integração espacial abrangente com o estado, com outros estados do país e, em menor escala, com outros países.

\section{Considerações Finais}

Este estudo com base na construção do setor de produção de energia no modelo insumo-produto do Rio Grande do Sul, para os anos de 1998 e 2003, teve como objetivo caracterizar os fluxos insumo-produto por origem e destino do setor energético, bem como avaliar a relevância de seus encadeamentos setoriais e a dependência produtiva com os componentes da demanda final.

A estrutura de compras de insumos mostrou que o setor em seu processo de produção utiliza pouco menos de $80 \%$ de insumos importados e apresenta um nível elevado de autoabastecimento de insumos domésticos. Já a estrutura de vendas evidenciou, por um lado, que mais de dois terços da produção de energia é consumido pelas indústrias do estado e, por outro lado, que o consumo das famílias e as exportações, em particular para outros estados, têm um peso significativo na demanda final de energia.

Os índices de ligações para trás com seus respectivos coeficientes de dispersão demostram que se trata de um setor com encadeamentos de compra pouco relevantes dentro da economia gaúcha, e seus estímulos, nos diversos setores da economia, pelo aumento da produção de energia, são pequenos e concentrados em poucos setores, ou seja, suas ligações para trás são fracas. Já os elevados ín- 
dices de ligações para frente com baixos coeficientes de dispersão conferem ao setor de produção de energia o status de um setor-chave fornecedor de insumos básicos, cuja produção estimula de forma abrangente e uniforme o crescimento nos demais setores produtivos da economia gaúcha.

As relações entre a produção de energia e os componentes da demanda final evidenciaram elevada dependência do setor pelo consumo das famílias e pelas exportações interestaduais, o que sugere que ocorreu maior produção de energia pelo aumento da renda das famílias e pelo crescimento econômico gaúcho com características históricas de ser um exportador tradicional. Cabe salientar, também, que os resultados obtidos são de alta relevância para o planejamento do estado, uma vez que, ao caracterizar a abrangência das relações do setor de produção de energia com os diferentes setores produtivos, fornecem subsídios para entender melhor não somente os impactos econômicos do consumo de energia, mas também, nas futuras pesquisas, o meio ambiente.

Entretanto, deve-se chamar a atenção de que neste trabalho não foram captados, por exemplo, os impactos da energia eólica, que a partir de 2006 passou a ser uma realidade importante no estado com a inauguração do parque eólico na região de Osório. Esse fato revela a necessidade de atualização das matrizes insumo-produto do Rio Grande do Sul para anos mais recentes, o que, certamente, permitirá captar com maior precisão as relações setoriais do setor de produção de energia com os diversos setores do estado e do país.

\section{Referências}

BULMER, V. Input-output analysis in developing countries. New York: John Wiley. 1982.

CAPELETTO, J. G.; MOURA, G. H. Z. Balanço Energético do Rio Grande do Sul 2010: ano base 2009. Porto Alegre: Grupo CEEE/Secretaria de Infraestrutura e Logística do Rio Grande do Sul, 2010. $240 \mathrm{p}$.

CHENERY, H. Regional analysis. In: CHENERY, H. B; CAO-PINA, V. The structure and growth of Italian economy. Rome: U.S. Mutual Security Agency, 1953.

HANSEN, W.; TIEBOUT, C. An intersectoral flow analysis of the California economy. The Review of Economics and Statistics, n. 45, p. 409-418, 1963.

HIRSCHMAN, A. The strategy of economic development. New Haven: Yale University Press, 1958.

MAIA NETO, A. A. (Coord.). Matriz de insumo-produto do Rio Grande do Sul 1998. Porto Alegre: FEE, 2002.

MONTOYA, M. A. A inserção insumo-produto da economia brasileira no Mercosul: uma abordagem pelo valor adicionado. Revista Brasileira de Economia. v. 55, n. 2, p. 253-282, abr.jun. 2001.

Análise insumo-produto internacional no Mercosul: desenvolvimento econômico e interdependência estrutural. Passo Fundo: EDIUPF, 1999. 
. Matriz insumo-produto internacional do Mercosul em 1990: a desigualdade regional e o impacto intersetorial do comércio inter-regional. 1998. Tese (Doutorado em Economia Aplicada - Escola Superior de Agricultura Luiz de Queiros (Esalq) da Universidade de São Paulo (USP), Piracicaba, 1998.

MONTOYA, M. A.; GUILHOTO, J. J. M. The interregional and intersectoral structure of Mercosur. An application, of input-output analysis. Australasian Journal of Regional Studies, v. 4, n. 1, p. 93-112, 1998.

MONTOYA, M. A.; PASQUAL, C. A.; BOGONI N. M. A inserção do setor produção de energia na economia do Rio Grande do Sul: uma abordagem insumo-produto. Passo Fundo: UFP, Cepeac-Feac, 2011. (Texto para discussão, n. 5).

MOSES, L. The stability of interregional trading patterns and input-output analysis. The American Economic Review, n. 45, p. 803-832, 1955.

POLENSKE, K. An empirical test of interregional input-output models: estimation of 1963 Japonese production. American Economic Review, v. 60, v. 2, p. 76-82, May 1970.

PORSSE, A. A. (Coord.). Matriz de Insumo-produto do Rio Grande do Sul 2003. Porto Alegre: FEE, 2007.

RASMUSSEN, P. N. Studies in inter-sectorial relations. Amsterdam: North-Holland, 1956. 
Anexo A - Agregação e Compatibilização Setorial das MIP e da Matriz Energética do Rio Grande do Sul

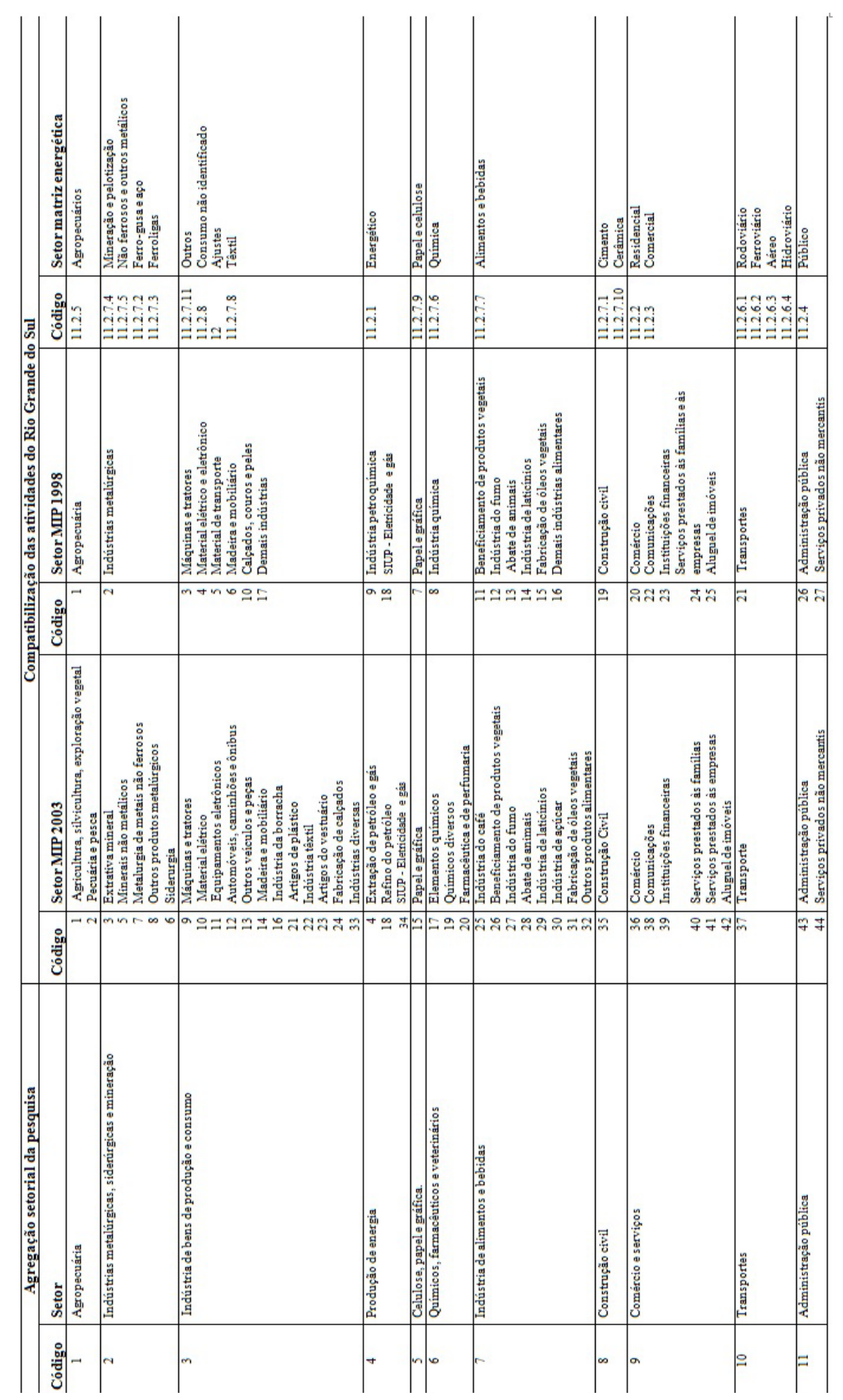

Fonte: Elaboração própria a partir dos dados da pesquisa. 
Anexo B - Matriz Insumo-Produto do Rio Grande do Sul com Setor de Produção de Energia para 1998 (valores em milhões de reais de 2010)

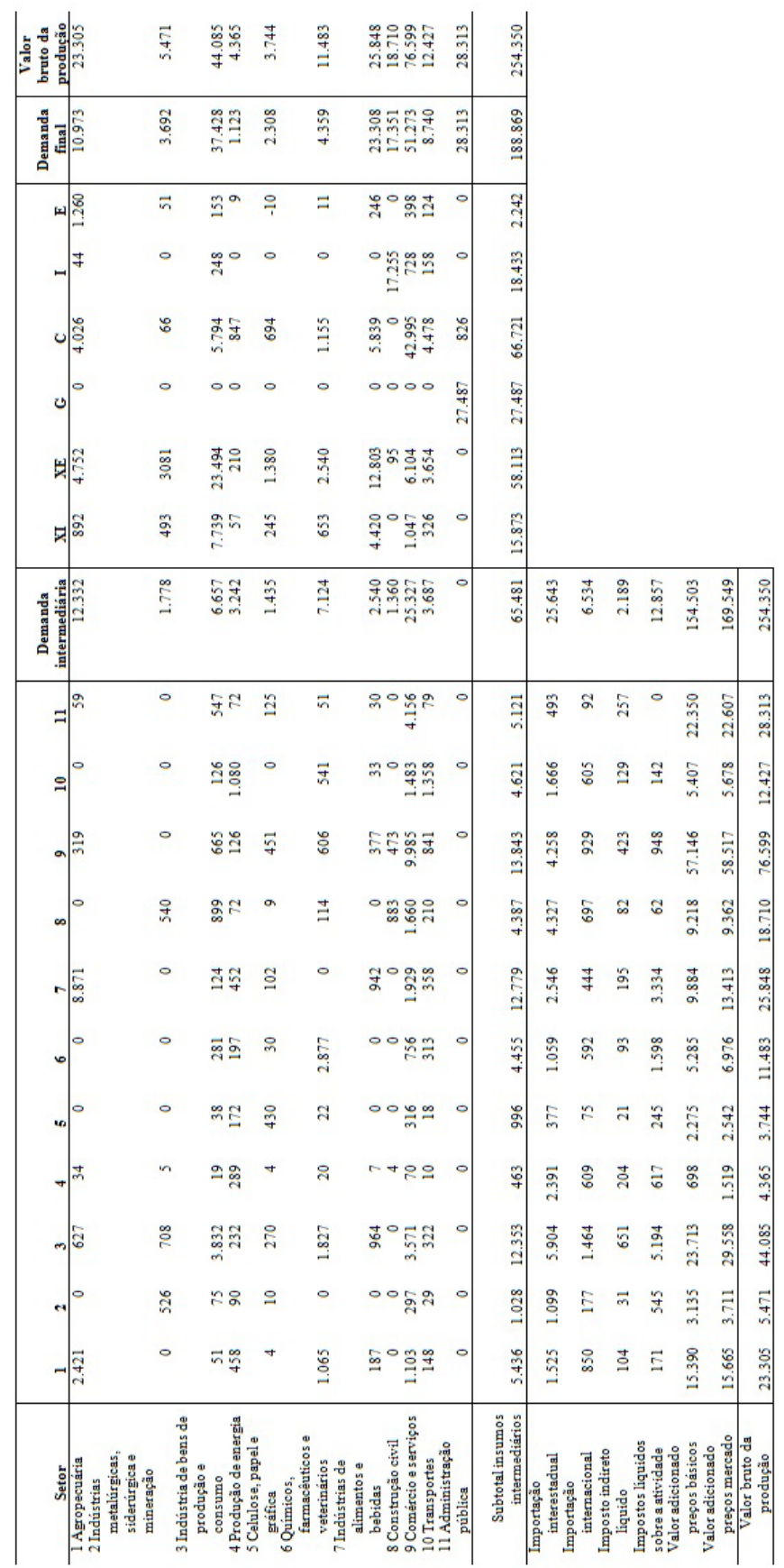

Fonte: Montoya, Pasqual e Bogoni (2011). 
Anexo C - Matriz Insumo-Produto do Rio Grande do Sul com Setor de Produção de Energia para 2003 (valores em milhões de reais de 2010)

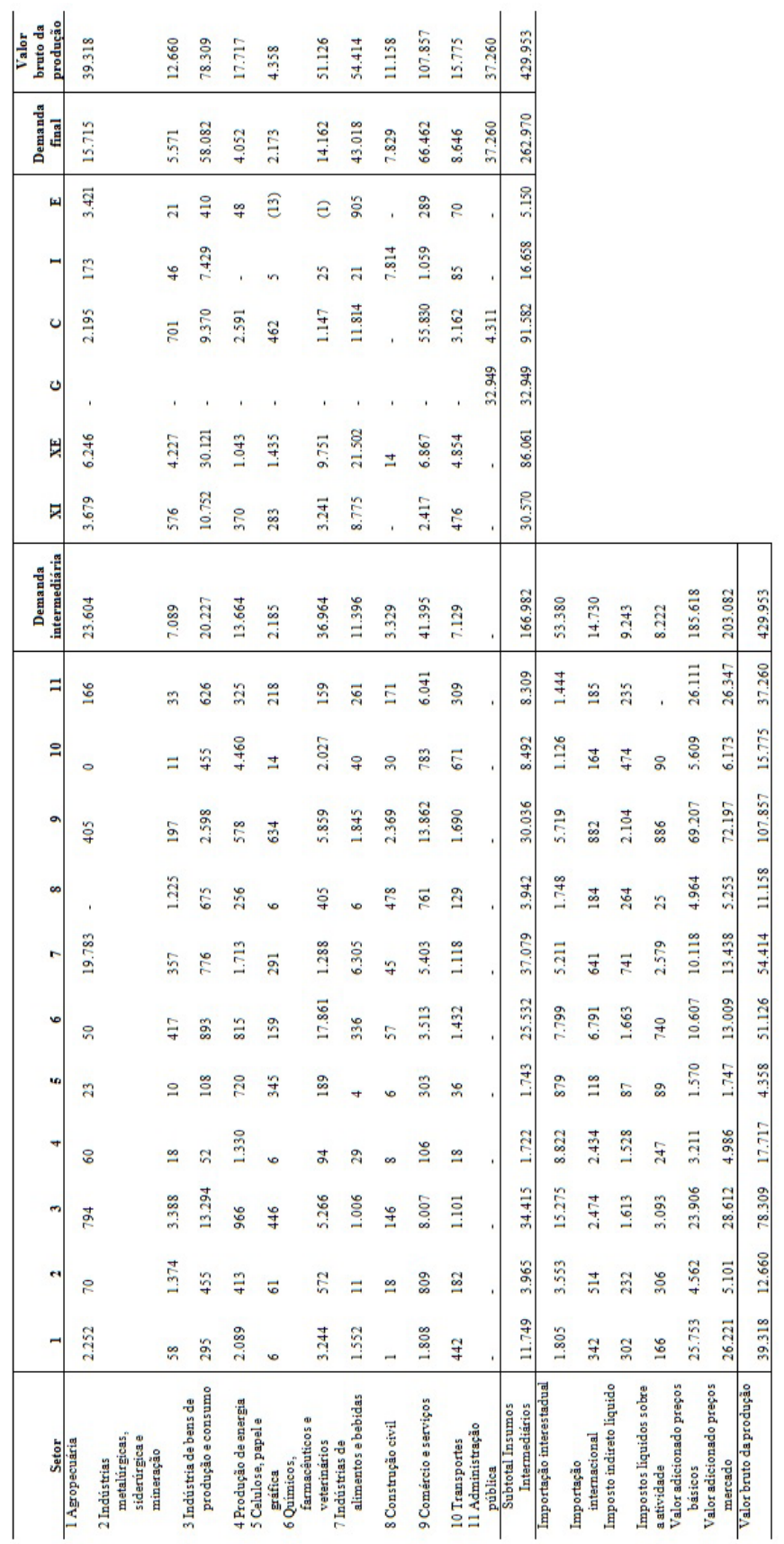

Fonte: Elaboração própria a partir dos resultados da pesquisa. 


\section{Anexo D - Produção Induzida pelos Componentes da Demanda Final para o ano de 1998 (valores em milhões de reais de 2010)}

\begin{tabular}{|c|c|c|c|c|c|c|c|c|}
\hline & \multirow[b]{2}{*}{$\begin{array}{l}\text { MIP RS } 1998 \\
\text { - Setor }\end{array}$} & \multicolumn{7}{|c|}{ Componentes da demanda final } \\
\hline & & $\begin{array}{l}\text { Exportação } \\
\text { internacional }\end{array}$ & $\begin{array}{l}\text { Exportação } \\
\text { interestadual }\end{array}$ & $\begin{array}{c}\text { Consumo } \\
\text { do } \\
\text { governo }\end{array}$ & $\begin{array}{c}\text { Formação } \\
\text { bruta de } \\
\text { capital } \\
\text { fixo }\end{array}$ & $\begin{array}{c}\text { Consumo } \\
\text { das } \\
\text { famílias }\end{array}$ & $\begin{array}{c}\text { Variação } \\
\text { de } \\
\text { estoque }\end{array}$ & Total \\
\hline 1 & Agropecuária & 2997 & 11178 & 125 & 7386 & 102 & 1518 & 23305 \\
\hline 2 & $\begin{array}{l}\text { Indústrias } \\
\text { metalúrgicas, } \\
\text { siderúrgica e } \\
\text { mineração }\end{array}$ & 699 & 3883 & 12 & 213 & 602 & 60 & 5471 \\
\hline 3 & $\begin{array}{l}\text { Indústria } \\
\text { de bens de } \\
\text { produção e } \\
\text { consumo }\end{array}$ & 8603 & 26267 & 638 & 7114 & 1277 & 186 & 44085 \\
\hline 4 & $\begin{array}{l}\text { Produção de } \\
\text { energia }\end{array}$ & 388 & 1633 & 118 & 2007 & 151 & 68 & 4365 \\
\hline 5 & $\begin{array}{c}\text { Celulose, papel } \\
\text { e gráfica }\end{array}$ & 385 & 1919 & 174 & 1229 & 40 & -4 & 3744 \\
\hline 6 & $\begin{array}{l}\text { Químicos, } \\
\text { farmacêuticos } \\
\text { e veterinários }\end{array}$ & 1602 & 5976 & 171 & 3315 & 284 & 134 & 11483 \\
\hline 7 & $\begin{array}{l}\text { Indústria de } \\
\text { alimentos e } \\
\text { bebidas }\end{array}$ & 4824 & 14058 & 71 & 6572 & 46 & 276 & 25848 \\
\hline 8 & $\begin{array}{l}\text { Construção } \\
\text { civil }\end{array}$ & 19 & 185 & 31 & 342 & 18129 & 4 & 18710 \\
\hline 9 & $\begin{array}{l}\text { Comércio e } \\
\text { serviços }\end{array}$ & 2880 & 12897 & 4770 & 52487 & 2945 & 620 & 76599 \\
\hline 10 & Transportes & 625 & 4998 & 159 & 6009 & 468 & 168 & 12427 \\
\hline 11 & $\begin{array}{l}\text { Administração } \\
\text { pública }\end{array}$ & 0 & 0 & 27487 & 826 & 0 & 0 & 28313 \\
\hline & Total & 23021 & 82995 & 33758 & 87502 & 24045 & 3029 & 254350 \\
\hline
\end{tabular}

Fonte: Elaboração própria a partir dos resultados da pesquisa. 


\section{Anexo E - Produção Induzida pelos Componentes da Demanda Final para o ano de 2003 (valores em milhões de reais de 2010)}

\begin{tabular}{|c|c|c|c|c|c|c|c|c|}
\hline & $\begin{array}{c}\text { MIP RS } 1998 \\
\text { - Setor }\end{array}$ & $\begin{array}{l}\text { Exportação } \\
\text { internacional }\end{array}$ & $\begin{array}{l}\text { Exportação } \\
\text { interestadual }\end{array}$ & $\begin{array}{c}\text { Consumo } \\
\text { do } \\
\text { governo }\end{array}$ & $\begin{array}{l}\text { Formação } \\
\text { bruta de } \\
\text { capital } \\
\text { fixo }\end{array}$ & $\begin{array}{c}\text { Consumo } \\
\text { das } \\
\text { famílias }\end{array}$ & $\begin{array}{l}\text { Variação } \\
\text { de } \\
\text { estoque }\end{array}$ & Total \\
\hline 1 & Agropecuária & 8235 & 17362 & 362 & 8816 & 423 & 4120 & 39318 \\
\hline 3 & $\begin{array}{l}\text { Indústria } \\
\text { de bens de } \\
\text { produção e } \\
\text { consumo }\end{array}$ & 13755 & 38720 & 942 & 14494 & 9792 & 606 & 78309 \\
\hline 5 & $\begin{array}{c}\text { Celulose, papel } \\
\text { e gráfica }\end{array}$ & 541 & 2215 & 264 & 1221 & 110 & 7 & 4358 \\
\hline 6 & $\begin{array}{l}\text { Químicos, } \\
\text { farmacêuticos } \\
\text { e veterinários }\end{array}$ & 8877 & 26033 & 1056 & 12336 & 2075 & 748 & 51126 \\
\hline 7 & $\begin{array}{l}\text { Indústria de } \\
\text { alimentos e } \\
\text { bebidas }\end{array}$ & 10704 & 26276 & 427 & 15490 & 275 & 1240 & 54414 \\
\hline 11 & $\begin{array}{c}\text { Administração } \\
\text { pública }\end{array}$ & 0 & 0 & 32949 & 4311 & 0 & 0 & 37260 \\
\hline & Total & 54515 & 152802 & 44009 & 143309 & 27036 & 8282 & 429953 \\
\hline
\end{tabular}

Fonte: Elaboração própria a partir dos resultados da pesquisa.

Recebido em: 20/08/2012.

Aceito em: 26/03/2013. 